\title{
Specific Chemotherapy Treatments for Patients with Ovarian Endodermal Sinus Tumors
}

\author{
Jiménez-Báez Maria Valeria ${ }^{\star, \dagger, 1,2}$, Maravilla-Ulloa Ilinova ${ }^{3}$, Rojas-López Brenda \\ Michelle$^{4}$, Quiroz-Valdes Berenice de Jesús ${ }^{5}$, Chavez-Hernández María Margarita ${ }^{6}$, \\ Sandoval- Jurado L ${ }^{7}$, Enrique Leobardo Ureña Bogarín ${ }^{8}$, Irma Archundia Riveros ${ }^{9}$ \\ ${ }^{1}$ Instituto Mexicano del Seguro Social. Delegación Quintana Roo. Grupo de Investigación Clínica del IMSS en Quintana Roo \\ (GRICIQ) \\ ${ }^{2}$ Teacher School of Medicine, Universidad Anáhuac Cancún \\ ${ }^{3}$ Teacher School of Medicine, Universidad Anáhuac Cancún \\ ${ }^{4}$ Student School of Medicine, Universidad Anáhuac Cancún \\ ${ }^{5}$ Student School of Medicine, Universidad Anáhuac Cancún \\ ${ }^{6}$ Instituto Mexicano del Seguro Social. Delegación Quintana Roo. Grupo de Investigación Clínica del IMSS en Quintana Roo \\ (GRICIQ) \\ ${ }^{7}$ Instituto Mexicano del Seguro Social. Delegación Quintana Roo. Grupo de Investigación Clínica del IMSS en Quintana Roo \\ (GRICIQ) \\ ${ }^{8}$ Instituto Mexicano del Seguro Social. Delegación Quintana Roo. Grupo de Investigación Clínica del IMSS en Quintana Roo \\ (GRICIQ) \\ ${ }^{9}$ Instituto Mexicano del Seguro Social. Delegación Quintana Roo. Grupo de Investigación Clínica del IMSS en Quintana Roo \\ (GRICIQ)
}

DOI: https://doi.org/10.15520/jcmro.v2i01.118

Accepted 16-01-2018; Received 07-01-2018; Publish Online 2019-01-20

Reviewed By:
Emmanuel Andres
Department: Professor
of Internal Medicine;
Head of the
Department of
Internal Medicine
France

Reviewed By: Department: Professor of Internal Medicine; Head of the Intepartment of France

\begin{abstract} Cells.
\end{abstract}

Ovarian endodermal sinus tumors are a neoplasm of germinal origin derived from the primordial cells that during their migration from the caudal area to the gonadal region undergo mutations that progress to become malignant cells that proliferate constantly. Appearance is unilateral; it is considered the germinal tumor with the highest malignancy rate. (20\%) Early diagnosis could increase patient survival. An exploratory investigation included the five last years in the pubmed, science, and Cochrane was carried out to evaluate the evidence of the diagnosis and / or treatment of these tumors. It was found that mortality is due to delayed diagnosis and ineffective treatment. It is necessary to determine the chemotherapy treatments that effectively attack this type of neoplastic cells, which behave differently from other types of tumors.

Key words: Tumor-Ovary-Endodermal Cells-Yolk Sac-Endodermal Sinus-Germ

\section{INTRODUCTION:}

Ovarian endodermal sinus tumors are a type of neoplasm of germinal origin that occurs mainly in childhood and in young age, have an incidence of 2.4 cases per million young people up to 15 years, the main cause of the presence of ovarian tumors in the first twenty years of life has its origin in germ cells (up to $70 \%$ of cases) and of these $33 \%$ will be malignant, the mortality of patients who suffer it, increases

\footnotetext{
* Corresponding author.

$\dagger$ Email: valeria.jimenezb@gmail.com
}

if these are not diagnosed and treated in a

timely manner. [1] Its main treatment is based on surgery and chemotherapy and the response to it depends on the effectiveness of the drug against the type of neoplastic cell, so it is important that the histotype of the tumors is determined from the moment of your diagnosis. [2]

Endodermal sinus tumors are derived from the primitive germ cells that undergo constant mutations when they migrate, and when they develop in the gonadal zone, they mutate into neoplastic cells that multiply constantly and condition the rapid progression of the disease. $[2,3]$ They are observed as ultrasound encapsulated, round or globular 


\section{Specific Chemotherapy Treatments for Patients with Ovarian Endodermal Sinus Tumors}

and solid tumors with cystic spaces in which the presence of alpha-fetoprotein is observed. [3]

In our country, ovarian cancer accounts for $4 \%$ of all neoplasms, according to figures from the histopathological record of neoplasms in Mexico, it is estimated that neoplastic ovarian diseases have a frequency of $13.4 \%$ in relation to malignant germ-cell tumors., with 2,910 cases reported during 2008, ranking third in malignant pelvic tumors. [4]

The clinical picture of the disease is based mainly on pelvic pain of acute type and abnormal growth of the abdomen in the pelvic region, may be accompanied by other symptoms such as nausea, vomiting, constipation, weight loss without apparent cause, urinary discomfort, fever, amenorrhea and vaginal bleeding, among others. [1-4]

The diagnosis of the disease is mainly clinical and this suspicion must exist, the digital rectal examination allows to identify infiltration of the tumor in the bottom of the Douglas pouch. The determination of alpha-fetoprotein, axial tomography, ecosonography are useful, the gold standard is the histopathological study to determine the type of neoplastic cells. Abdelouhab, A, Mounir, K, Rachid, O, Maria, K, Najat, M, Aouatef C, Amine B.K, Mbarek A, Mohamed K, Zaitounia A, Mohamed N.B. Ovarian tumours in children : A review of 18 cases. Abdelouhab, A, Mounir, K, Rachid, O, Maria, K, Najat, M, Aouatef C, Amine B.K, Mbarek A, Mohamed K, Zaitounia A, Mohamed N.B. Ovarian tumours in children : A review of 18 cases. [5]

According to the world organization of health in the histological classification of germ tumors, three categories are described: [1, 2] Primitive germ cell tumors: Disgerminomas, which are usually bilateral even in $10-15 \%$, yolk sac tumors, known also as endodermal sinus tumors, embryonal carcinoma, polyembryoma, non-gestational choriocarcinomas and mixed germ cell tumors. 2) Biphasic or three-phase teratoma: immature teratomas and solid or cystic matures (dermoid cyst). 3) Monodérmico teratoma and somatic tumors associated to dermoid cysts: carcinoids, thyroid group, melanocytic, tumors of the neu-roepitelio, carcinomas, sarcomas and others.

In children it is estimated that the approximate incidence of this type of tumors is 2.6 cases per year / 100 000 girls, most of whom are diagnosed by the most common symptoms that present as abdominal pain and alterations in the menstrual cycle, in addition that these tumors, depending on their stage, can easily be recognized by radiography. [5] [6]

On average, an endodermal breast tumor treatment should cause remission of neoplastic cells around the 5th cycle of chemotherapy, it should have a follow-up of 57 months to determine remission. [4]

It is important that the management of this information is provided to health personnel since only $5 \%$ of neoplastic ovarian diseases are diagnosed and treated in a timely manner. [5]

The specific management of these tumors will contribute to the reduction of expenses in unnecessary treatments, since the costs of chemotherapy are extremely high and often these treatments are not effective. [5]
There are several biomarkers indicative of the existence of germ cells that help the histological differentiation of them one of the main ones is alpha-fetoprotein (AFP), which is elevated in the case of yolk sac tumors. [6]

For women with ovarian tumors of undetermined malignant potential, close monitoring with serial ultrasonography and biomarker determinations at 4 -week intervals for 3 months can provide valuable data on which to base a treatment decision. [7]

The purpose of the research is to provide the medical area with essential information for the management of endodermal breast tumors, to determine which treatment based on chemotherapy would be the most appropriate for this type of neoplasms.

\section{METHODS:}

A retrospective chart review of all cases of CCC referred between 2011 and 2018 was conducted. Data were collected from those with primarily advanced disease and from those who recurred after adjuvant treatment, in the Pubmed, Science and Cochrane databases over the last five years to evaluate the evidence for the diagnosis and / or treatment of these tumors. Outcomes were measured using broad definitions of treatment benefit (any objective or subjective evidence of disease control) in order to reflect the real-life use of palliative therapy. (diagram 1).Figure 1

\section{DISCUSSION:}

After reviewing the literature, it was determined that ovarian endodermal sinus tumors should reject neoplastic cells around the fifth cycle of chemotherapy, and the main success of the treatment is related to the timely diagnosis and specific use of the drugs They attack this type of cells directly without creating resistance. [8]

The treatment of chemotherapy indicated for neoplastic tumors of endodermal sinus (germinal origin), is based on bleomycin, etoposide and platinum (BEP), administered during 4 cycles should cause the remission of neoplastic cells in about $90 \%$ of the cases diagnosed and treated in a timely manner, and a follow-up of 78 months after the remission is determined. (One) [9]

In the review carried out, it is maintained that for this type of neoplasms the chemotherapy treatment that offers the best results is the one indicated for all the germinal neoplastic cells (BEP), which was not applied in the patient and that could make weight in the survival of it. Although the criterion for selecting treatment is unknown, it could be justified mainly due to the limited scope of chemotherapy treatments, their high cost and the socioeconomic status of the patient. [10]

We agree with the literature consulted that not only endodermal sinus tumors but all neoplasms and mainly those of germinal origin, should be diagnosed opportunely, since this is the main factor that could be indicative of a good prognosis, giving knowing the characteristics of this type of 


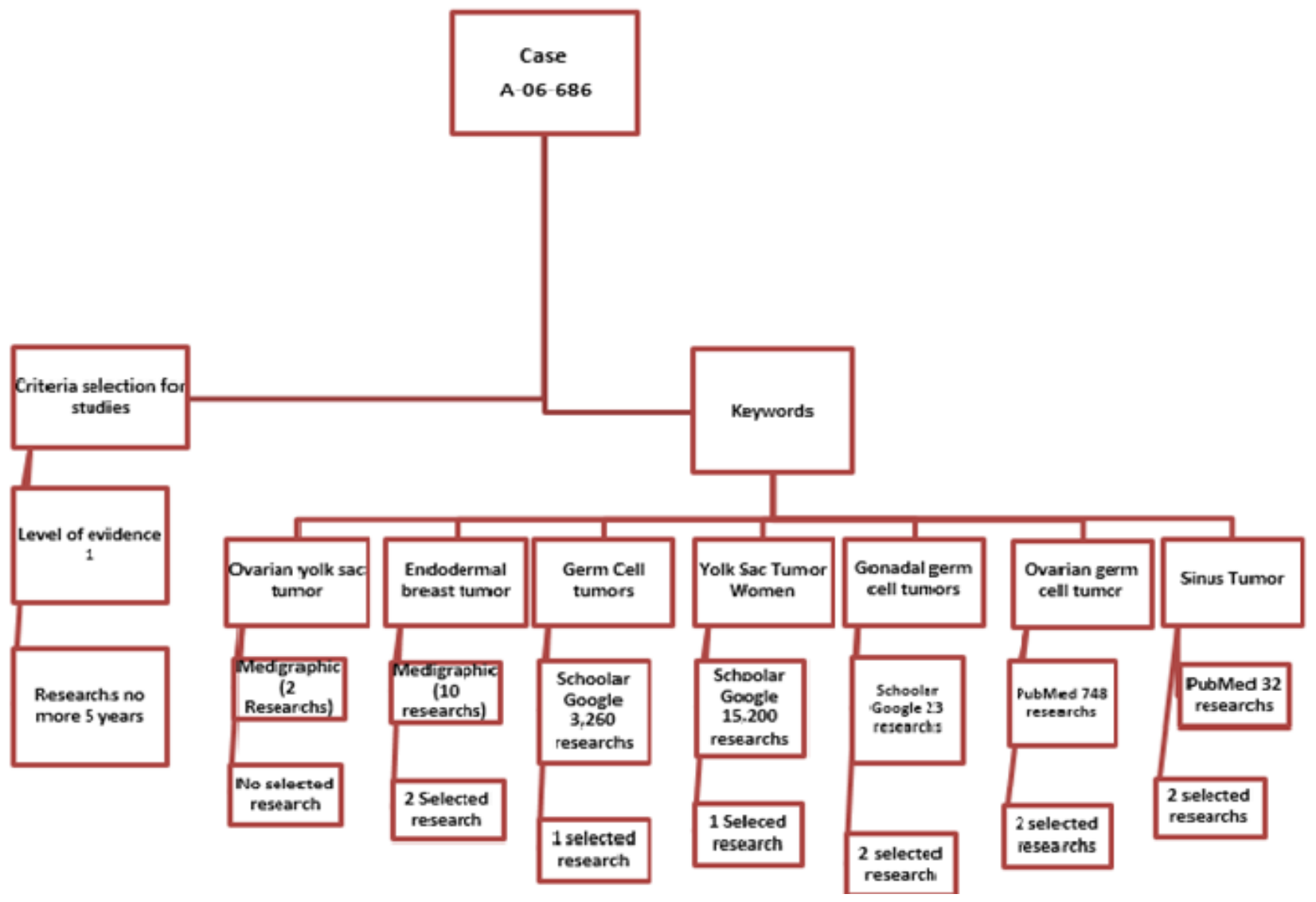

Figure 1.

neoplasms, the age ranges in which they are presented, the confirmatory tests and the specific treatment, are a very useful tool that can contribute to improve the quality of life of the patients after their diagnosis.

The research focused on the type of specific treatment that could be used as a first tool to combat this type of cancer, so the literature review of a broad field of research based on reliable information bases was carried out in order to distinguish in first stay what are the signs and symptoms of this condition, how often it can be given and in what age of the population it is easier to be present.

Ovarian endodermal sinus tumors are a neoplasm of germinal origin that have a rapid progression which determines that the diagnosis must be early and the treatment to be applied must be specific for germ cell tumors, since after the investigation it was found that they respond differentially to different types of chemotherapy treatments because their origin and structure differ from other types of tumors. They are infrequent but their level of malignancy is related to late diagnosis and poor treatment applied, they occur mainly in childhood and in young age having their highest incidence around 20 years of age.

In a ten years cohort with 47 patients the mean time to recurrence was 19 months after fertility-sparing surgery versus 20 months after radical surgery $(\mathrm{P}=0.935)$. The anatomical location of recurrence did not differ. There was no differ- ence in 5-year disease-free survival ( $77 \%$ vs $84 \% ; \mathrm{P}=0.849)$ or 5 -year overall survival ( $91 \%$ vs $88 \%$; $\mathrm{P}=0.480$ ). Only in FIGO stage I clear cell carcinoma of the ovary who wish to preserve fertility. [11]

In 2019 Nasioudis and Cols, observed in 741 premenopausal women diagnosed with unilateral stage IA or IC Ovarian Clear Cell Carcinoma (OCCC), who did not undergo hysterectomy and/or bilateral salpingo-oophorectomy (BSO) were identified, with an Kaplan - Meier curves, an log-rank test compared survivent, $14.5 \&$ in uterine preservation, ovarian preservation $28.1 \%$. After stage IA was not associated with mortality. [12]

The treatment of these is based on surgery and BEP chemotherapy (bleomycin, etoposide and platinum). It was found that the combination of these drugs plus early diagnosis determines survival to this condition.

\section{CONCLUSIONS}

Most patients with advanced or recurrent CCC have a low benefit-to-failure ratio from palliative CT. The role of RT and targeted agents must be explored to improve clinical outcomes for such patients. It is essential that health personnel have knowledge of the specific treatment of germ cell tumors, since this could contribute to the rejection of treat- 
ment and in turn become a determinant for the survival of patients.

\section{REFERENCES}

[1] Vargas-Hernández V, Vargas-Aguilar V, Acosta-Altamirano G, Garcia-Rodriguez F, Jimenez-Vilanueva X, MorenoEutimio M. Tumor de células germinales de ovario. Presentación clínica y su tratamiento en 15 casos;. en línea] Rev Hosp Jua Mex 2014; 81(4): 214-219. Disponible en.

[2] Torres-Lobaton A. Tumores malignos de células germinales del ovario. Estado actual de su diagnóstico y tratamiento;. en línea] Ginecol Obstet Mex. 2014;82:177-187. Disponible en.

[3] Secretaria de salud. Consejo nacional de excelencia tecnológica en salud. Abordaje diagnóstico y referencia del tumor pélvico ginecológico con sospecha de malignidad;. editorial]. [en línea] 2011. Disponible en. Available from: http://www. cenetec.salud.gob.mx/descargas/gpc/CatalogoMaestro/ 511_GPC_Tumor_pxlvico/GER_TumorPelvico.pdf.

[4] Bautista D, Ariza-Varon M, Medina-Vega D, RestrepoÁngel F, Ballesteros AL, Jaramillo E, et al. Molina-Ramirez I, Sarmiento-Urbina I. Tumores germinales gonadales en niños: experiencia de 20 años en un centro de referencia pediátrico. Fac Med;2015(63):47-56. en línea] Rev.

[5] Abdelouhab A, Mounir K, Rachid O, Maria K, Najat M. Aouatef C, Amine B.K, Mbarek A, Mohamed K, Zaitounia A, Mohamed N.B. Ovarian tumours in children : A review. of;18. en línea] AJPS. 2012;9(3): 231-236. Disponible en línea. Available from: http://www.afrjpaedsurg.org/article. asp.

[6] González G. Tumores sólidos en niños: Diagnóstico y terapéutica quirúrgica;. en línea] Rev Med Clin Condes. 2010;21(1): 120-129. Disponible en.

[7] Rensselaer J, Ware R. Evaluación y Manejo de Tumores Ováricos Detectados por Ultrasonido en Mujeres Asintomáticas. Obstet;127:848-58. Disponible en.

[8] jie Y U X, Lin Z, ping Liu Z, Shi YQ, xin Liu Y. Case Report Ovarian malignant mixed germ cell tumor with clear cell carcinoma in a postmenopausal woman. Int J Clin Exp Pathol;2014(12):8996-9001.

[9] Masafumi K, Noriomi M, Ikuo K. Review Article Recent Concepts of Ovarian Carcinogenesis: Type I and Type II. BioMed Research International;2014(1):1-11.

[10] Brito Y, Caravia F, Hernández D, González A, Massip J. Treatment results in patients with ovarian cancer during 2001-2013. Medicent Electrón;2016(20):259-267.

[11] Park JY, Suh DS, Kim JH, Kim YM, Kim YT, Nam JH. Outcomes of fertility-sparing surgery among young women with FIGO stage I clear cell carcinoma of the ovary. Int J Gynaecol Obstet;2016:134-1. Available from: http://www. ncbi.nlm.nih.gov/pubmed/27039052.

[12] Nasioudis D, Chapman-Davis E, Frey MK, Witkin SS, Holcomb K. Could fertility-sparing surgery be considered for women with early stage ovarian clear cell carcinoma? J Gynecol Oncol;2017:28-6. Available from: http://www.ncbi. nlm.nih.gov/pubmed/28758377. 